\title{
Corinna Körting
}

Der Schall des Schofar

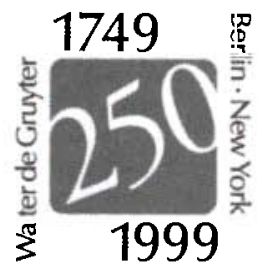




\title{
Beihefte zur Zeitschrift für die alttestamentliche Wissenschaft
}

\author{
Herausgegeben von \\ Otto Kaiser
}

Band 285

\begin{tabular}{l}
$W$ \\
DE \\
\hline
\end{tabular}

Walter de Gruyter · Berlin · New York 1999 
Corinna Körting

\section{Der Schall des Schofar}

Israels Feste im Herbst

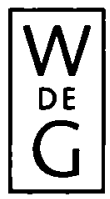

Walter de Gruyter - Berlin - New York 1999 
@ Gedruckt auf säurefreiem Papier, das die US-ANSI-Norm über Haltbarkeit erfüllt

Die Deutsche Bibliothek - CIP-Einheitsaufnabme

[Zeitschrift für die alttestamentliche Wissenschaft / Beihefte] Beihefte zur Zeitschrift für die alttestamentliche Wissenschaft. Berlin ; New York : de Gruyter.

Früher Schriftenreihe

Reihe Beihefte zu: Zeitschrift für die alttestamentliche Wissenschaft

\section{Körting, Corinna:}

Der Schall des Schofar : Israels Feste im Herbst / Corinna Körting. Berlin ; New York : de Gruyter, 1999

(Beihefte zur Zeitschrift für die alttestamentliche Wissenschaft ; Bd. 285)

Zugl.: Hamburg, Univ., Diss., 1998/99

ISBN 3-11-016636-4

(C) Copyright 1999 by Walter de Gruyter GmbH \& Co. KG, D-10785 Berlin.

Dieses Werk einschließlich aller seiner Teile ist urheberrechtlich geschützt. Jede Verwertung außerhalb der engen Grenzen des Urheberrechtsgesetzes ist ohne Zustimmung des Verlages unzulässig und strafbar. Das gilt insbesondere für Vervielfältigungen, Übersetzungen, Mikroverfilmungen und die Einspeicherung und Verarbeitung in elektronischen Systemen.

Printed in Germany

Druck: Werner Hildebrand, Berlin

Buchbinderische Verarbeitung. Lüderitz \& Bauer-GmbH, Berlin 
Für Oliver 
